\title{
Salvianolic Acid B Ameliorates Motor Dysfuntion in Spinal Cord Injury Rats
}

\author{
Chong Xun, Shouyu Wang, Guang Chen, Yang Hu, Jiaqi Xie and Decheng Lv* \\ Department of Surgery, The First Affiliated Hospital of Dalian Medical University, Dalian, 116000, PR China.
}

*For correspondence: Email: Ivdecheng777@hotmail.com; Tel: +86 0411-86724517,

\begin{abstract}
Purpose: To evaluate the effect of salvianolic acid B (Sal B) treatment on the motor function of spinal cord injury (SCl) rat.

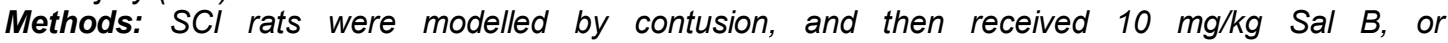
methylprednisolone, or phosphate-buffered saline (PBS) intraperitoneally daily for 4 weeks, two hours after the trauma occurred. During the treatment, footprint analysis (FA), inclined plane test (IPT), BassoBeattie-Bresnahan (BBB) rating and Schnell Swim Test (SST) were used for estimating the recovery of motor function. At the same time, tissue edema was measured by wet-dry weighting, and the secretion of cytokines were indirectly quantitated by real time polymerase chain reaction (qPCR).

Results: Primarily, Sal B group rats scored higher by FA, IPT and BBB rating. Further statistical analysis of comprehensive SST data from Student-t test indicates that Sal B can significantly ameliorate motor dysfunction after a 4-week treatment $(p<0.05)$ as well. Furthermore, Sal B decreased water content of the edema by $16.5 \%$ during the first week, and sharply downregulated the transcription of interleukin 6 (IL-6) and tumor necrosis factor (TNF- $\alpha$ ) 28- and 16-fold, respectively.

Conclusion: The beneficial effect of motor function recovery was observed in SCl rats following intraperitoneal administration of Sal $B$.
\end{abstract}

Keywords: Salvianolic acid B, Spinal cord injury, Motor dysfunction, Cytokines

\begin{abstract}
Tropical Journal of Pharmaceutical Research is indexed by Science Citation Index (SciSearch), Scopus, International Pharmaceutical Abstract, Chemical Abstracts, Embase, Index Copernicus, EBSCO, African Index Medicus, JournalSeek, Journal Citation Reports/Science Edition, Directory of Open Access Journals (DOAJ), African Journal Online, Bioline International, Open-J-Gate and Pharmacy Abstracts
\end{abstract}

\section{INTRODUCTION}

$\mathrm{SCl}$ refers to injuries occurred to the spinal cord, it may be caused by primary injury due to trauma, and secondary injury due to the cascade of cellular and molecular events that after trauma $[1,2]$. Depending on where the spinal cord and nerve roots are damaged, the symptoms can vary widely, from pain to paralysis. In the United States, the incidence of $\mathrm{SCl}$ has been estimated to be about 40 cases per million population per year, and there are around 265,000 individuals living with $\mathrm{SCls}$ at present with over $80 \%$ occurrence in males [3]. The prevalence of $\mathrm{SCl}$ is approximately 60,000 per year in China according to a recent report [4].

A traditional Chinese medicine, Salvia miltiorrhiza has been widely used in Asian countries for the treatment of cardiovascular and cerebrovascular diseases [5]. Currently, two major components extracted from the root of $S$. miltiorrhiza are Tanshinone IIA and salvianolic acid B (Sal B). The antioxidant Sal B has been shown to improve functional recovery in braininjured rats and provide neuroprotective effects in some experimental models of cerebral ischemia [6,7]. Recently, Deng et al. reported that Sal B improved motor function are partially 
due to inhibition of increased TNF- $\alpha$ in the damaged spinal cord and exhibits neuroprotective effects $[8,9]$.

The present study was designed to determine whether Sal B could be reliably used for motor function repairing in $\mathrm{SCl}$ rats. With the contusion animal models, a series of tests were used for evaluating the capacity of Sal B treatment on SCI rats. By multiple-factor comparison, we confirmed the effectiveness of the Sal B treatment and shown how much extent it can be improved critically in terms of the motor function. Except for direct damage to the spinal cord from trauma, the secondary injuries are important for $\mathrm{SCl}$ treatment. Therefore, we also measured tissue edema and changes of cytokines in the spinal cord contusion model.

\section{EXPERIMENTAL}

\section{Animals and drugs}

Healthy Sprague Dawley rats (40), weighing 220 to $250 \mathrm{~g}$ ( 7 weeks old, male), were supplied by the Animal Center of Dalian Medical University, China. All the animals were housed at $25{ }^{\circ} \mathrm{C}$ in polycarbonate cages, 5 rats fed in one cage under controlled lighting (12 h light-dark cycle). Rats had free access to standard rodent water and chow throughout the experiment. Protocols were conducted in accordance with the latest Guide for the Care and Use of Laboratory Animals [10]. The standard chemical solution of Sal B was purchased from National Institute for the Control of Pharmaceutical and Biological Products (Beijing). PBS solution and methylprednisolone were purchased from Selleck (Shanghai, China).

\section{Establishment of $\mathrm{SCl}$ model and treatment}

Sprague Dawley rats (30) were subjected to acute spinal segment injury by contusion [11]. Briefly, the rats were intraperitoneally anesthetized using $0.4 \%$ chloral hydrate (40 $\mathrm{mg} / \mathrm{kg}$ ). The injury was introduced by impact force $(20 \mathrm{~g}, 2.5 \mathrm{~cm})$ to the segments T11 and T12 of spine, damage in which leading to paralysis of the leg muscles above and below the knee in human. The success of $\mathrm{SCl}$ model establishment was affirmed with the posterior limbs of retraction-like flutter and flaccid paralysis. The other 10 rats without $\mathrm{SCl}$ were housed in two cages as healthy control. For each group, animals were treated as folllowing: 10 rats were intraperitoneally administered with 10 $\mathrm{mg} / \mathrm{kg}$ Sal $\mathrm{B}, 10$ rats with exactly the corresponding volume of PBS, and other 10 rats with $10 \mathrm{mg} / \mathrm{kg}$ methylprednisolone, respectively.
All treatments began at 2 hours after injury, and lasted for 4 weeks with 24 hours interval.

\section{Test of tissue edema}

All forms of injury can cause spinal cord edema, further decreasing blood flow and oxygenation. Edema is one of the secondary events which might aggravate a primary injury and there are reasons to believe that compounds, like SalB, might be useful to ameliorate the adverse effect. As one of the most important traditional herbal medicines, it is widely used in clinic in China, Japan, and other countries for the treatment of coronary artery disease and other cardiovascular diseases. The wet and dry weight method was used to evaluate the extent of tissue edema [11].

\section{Evaluation of behavioral defect}

A variety of methods have been used to assess animal functional recovery after SCI. FA is one of the widely used non-invasive and quantitative method [12]. A series of at least six sequential steps were used to determine the mean values for measurement in a 5-point scoring system. The observation was conducted at the end of every week. IPT has been used routinely in models of $\mathrm{SCl}$ to clearly quantify the functional deficits due to major trauma to the central nervous system, which was modified from previously reported methods [13]. This technique requires the rat to maintain its position for 5 seconds on a movable plane when the angle is adjusted by $1^{\circ}$ inclination from $40^{\circ}$ to a maximum of $55^{\circ}$. The maximum angle at which the rat can keep its position was recorded. The test was conducted once a week. BBB locomotor scale, the most widely used open field test has been accepted as a valid way to assess locomotor function after $\mathrm{SCl}$ in the rat [14]. All the rats were allowed to adapt for 5 min after they were moved out to an open field. The movement of each animal was recorded by a digital camera and subsequently scored by the evaluators, who were blind to the treatment of the injuries. A more comprehensive method, SST was proposed to measure motor function and recovery in spinal cord injured rats [15]. In this work, we measured: the velocity, forelimb strokes, tail movement, and the position of hindpaw. SST was conducted at the end of the treatment.

\section{Cytokine detection by qPCR}

Total RNA was extracted from injured tissue samples using the RNAeasy Kit (Qiagen, Germany) and $1 \mu \mathrm{g}$ total RNA was used for cDNA synthesis with oligo dT and MMLV-RT purchased from Invitrogen. A total of $2 \mu \mathrm{L}$ cDNA 
was subjected to mRNA quantification using SYBR Green PCR Master Mix (Applied Biosystems, CA, USA). Briefly, quantitative PCR was performed using Roche LightCycler 480 for 40 cycles at $95^{\circ} \mathrm{C}$ for $10 \mathrm{~s}$, specific annealing temperature for $5 \mathrm{~s}$ and annealing at $72{ }^{\circ} \mathrm{C}$ for 10 s. Amplification specificity was checked using melting curve following the manufacturer's instructions. All experiments were performed twice in triplicate; all primers used were synthesized by Invitrogen (Shanghai, China) according to reference [16], sequence details are listed in Table 1.

\section{Statistical analysis}

The results are expressed as mean \pm standard deviation (SD). Statistical comparison between control and the drug-treated groups were performed using Student-t test for in vivo data, $P$ $<0.05$ was set as the level of significance.

\section{Ethical approval}

This study was approved by the Animal Ethics Committee of Dalian Medical University, China.

\section{RESULTS}

\section{Water content of edema tissue decreased after Sal B therapy}

Three rats from the $\mathrm{SCl}$ group were randomly chosen for tissue edema test after 1, 3, and 7 days treatment. Water content in the spinal cord significantly decreased after 3 days in the model group treated with $10 \mathrm{mg} / \mathrm{kg}$ Sal B (Table 2; P $<0.05)$. Methylprednisolone can ameliorate tissue edema as well, though less effective than Sal B. After 7 days injection of Sal B, the edema tissue of $\mathrm{SCl}$ rats contained only $66.8 \%$ water, which is about $10 \%$ less than that for PBS-treated rats.
Sal $B$ ameliorates motor deficits evaluated by FA, IPT, BBB, SST

Sal B-treated rats showed higher score after one week, and the scores increased over the following 3 weeks (Fig 1). This gait demonstrated a significant improvement in the Sal B-treated rats compared with the controls. Obviously, the improvement is much greater after 3 weeks injection.

Table 2: Injured spinal cord water content (\%)

\begin{tabular}{|c|c|c|c|}
\hline \multirow[t]{2}{*}{ Group } & \multicolumn{3}{|c|}{ Days after $\mathrm{SCl}$} \\
\hline & 1 & 3 & 7 \\
\hline PBS & 83.3 & 80,1 & 76.5 \\
\hline Sal B & 75.6 & $71.2^{* *}$ & $66.8^{* *}$ \\
\hline Methylprednisolone & 78.4 & 75.7 & 72.9 \\
\hline
\end{tabular}

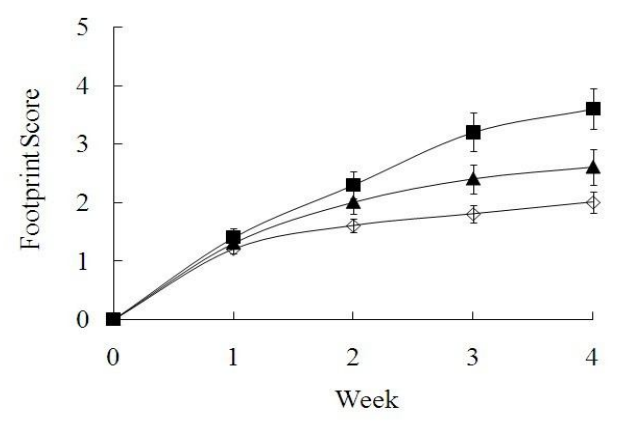

Fig 1: Weekly FA of rats after treated with different chemicals. Values are scored as following standards: 0 , no constant dorsal stepping or hindlimb dragging; 1 , at least three toes in three footprints; 2 , rotation of the feet more than double; 3 , no signs of toe dragging but foot rotation; 4 , no signs of rotation but more than one visible heel print; 5 , no visible heel prints. PBS, Sal B and Methylprednisolone are $\mathrm{SCl}$ rats treated with them respectively. Error bars indicate SEM; $n=10$ animals per group. Key: $\diamond=$ PBS group; $\boldsymbol{\square}=$ Sal B group; $\boldsymbol{\Delta}=$ methylprednisolone group.

Table 1: Primers used for amplification of cytokines and corresponding amplicons

\begin{tabular}{|c|c|c|c|c|}
\hline Gene name & Primer & Sequence & cDNA position & Accession no. \\
\hline IL-1a & FW & AAGACAAGCCTGTGTTGCTGAAGG & $663-747$ & D00403 \\
\hline IL-1 $\beta$ & $\begin{array}{l}\text { RW } \\
\text { FW }\end{array}$ & $\begin{array}{l}\text { TCCCAGAAGAAAATGAGGTCGGTC } \\
\text { CACCTCTCAAGCAGAGCACAG }\end{array}$ & $793-871$ & M98820 \\
\hline IL-6 & $\begin{array}{l}\text { RW } \\
\text { FW }\end{array}$ & $\begin{array}{l}\text { GGGTTCCATGGTGAAGTCAAC } \\
\text { TCCTACCCCAACTTCCAATGCTC }\end{array}$ & $532-610$ & E02522 \\
\hline TNF- $\alpha$ & $\begin{array}{l}\text { RW } \\
\text { FW }\end{array}$ & $\begin{array}{l}\text { TTGGATGGTCTTGGTCCTTAGCC } \\
\text { AAATGGGCTCCCTCTCATCAGTTC }\end{array}$ & 195-305 & X66539 \\
\hline$\beta$-Actin & $\begin{array}{l}\text { RW } \\
\text { FW }\end{array}$ & $\begin{array}{l}\text { TCTGCTTGGTGGTTTGCTACGAC } \\
\text { AAGTCCCTCACCCTCCCAAAAG }\end{array}$ & $3474-3570$ & J00691 \\
\hline & RW & AAGCAATGCTGTCACCTTCCC & & \\
\hline
\end{tabular}


Healthy rats can stay for 5 seconds on an inclined plane at an angle of $52^{\circ}$. However, the $\mathrm{SCl}$ rats treated with $\mathrm{PBS}$ as negative control after 1 week could only maintain their position at a much lower angle of, $42^{\circ}$ exactly, while, the injuried rats that received $10 \mathrm{mg} / \mathrm{kg}$ Sal $B$ demonstrated much stronger capacity to move on the plane at an angle as high as $49^{\circ}$ (Fig 2). Even, following treatment (weeks 2 - 4) steadily enhanced this beneficial effect, but the improvement was clearly not as distinct as the first week.

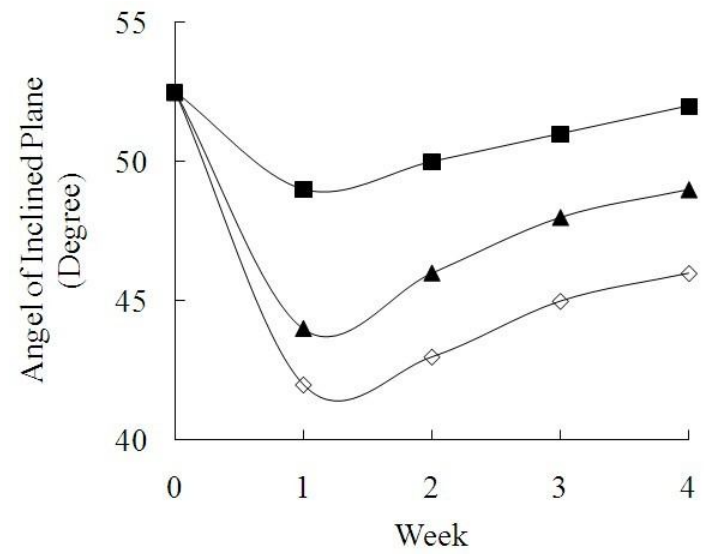

Fig 2: Motor disturbances of the rat hindlimbs after $\mathrm{SCl}$, using an inclined plane test. Key: $\diamond=$ PBS

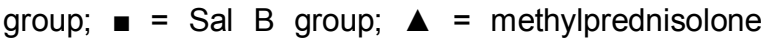
group.

On the first day, all rats scored less than 4, indicating the contusion caused severe damage to motor function. And then, scores of all groups were increased greatly after treatment for 7 days (Fig 3). However, the trend becomes slower after two weeks for Sal B treated group even its score is still much higher than other groups.

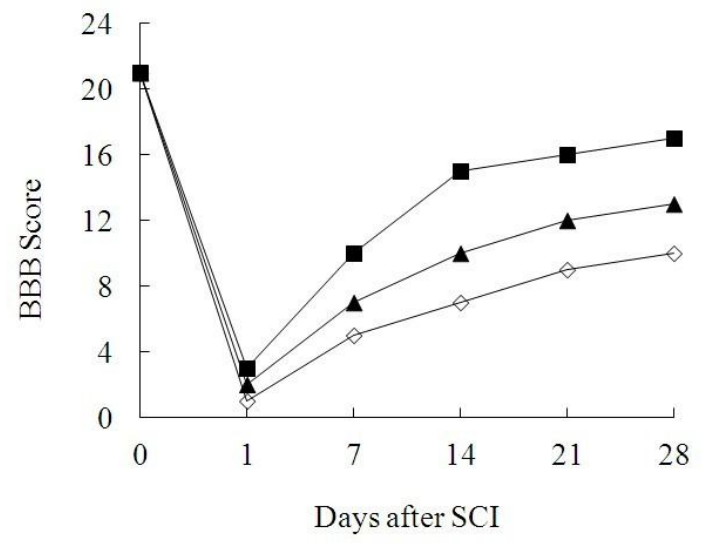

Fig 3: Temporal effect of different chemicals on motor disturbances after SCI by BBB rating. Key: $\diamond=$ PBS group; - = Sal $\mathrm{B}$ group; $\boldsymbol{\Delta}=$ methylprednisolone group.
Velocity and forelimb strokes, two objective measurable parameters, correlated with the extent of the lesions and allow the assessment of recovery after treatment. As demonstrated in Fig 4A, the PBS-treated rats swam more slowly than Sal B-treated rats, meaning Sal B improved the velocity of $\mathrm{SCl}$ rats significantly than the other two counterparts. In Fig 4B, Sal B treatment decreased the stroke of forelimb more than $10 \%$ compared to PBS group. Meantime, the position of the hindpaws of the Sal B-treated $\mathrm{SCI}$ rats was closer to the body axis relative to the PBStreated rats whose hindpaws deviated to a more lateral position (Fig 4D). However, there was little influence of these treatments on the movement of tails when swimming of the rats was observed in this test (Fig 4C).

We utilized SYBR Green qPCR protocol to assay pro-inflammatory cytokines (IL-1 $\alpha$, IL-1 $\beta$ and IL6 , TNF- $\alpha$ ), normalized with the housekeeping genes $\beta$-actin. Based on Figure 5 , the transcription of IL-1 is basically resistant to the treatment. More specifically, IL-1 $1 \alpha$ seems to have little contribution to $\mathrm{SCl}$ and its treatment, even IL-1 $\beta$ transcription was upregulated about 6 times. The most striking results came from comparisons of IL-6 and TNF- $\alpha$. Obviously, the abundance of IL- 6 and TNF- $\alpha$ is much higher in $\mathrm{SCl}$ rats. However, Sal B treatment can significantly downregulate the transcription of IL6 and TNF-a, about 28-fold and 16-fold respectively. The sharp fluctuations of IL- 6 and TNF- $\alpha$ may play important role in the recovery of motor function to a certain extent

\section{DISCUSSION}

In the experimental treatment of $\mathrm{SCl}$, the behavioral test depends on the injury model. Moderate or mild injuries can be simulated using devices such as weight drop, which will lead to a compression-type injury to the spinal cord [17]. Thus the animals tend to show limitation in the substantial use of their hind limbs due to the survival of axonal pathways.

Many tests are sensitive to this region of functionality including IPT and FA among others [18]. IPT has added utility since it does not require an extensive training period or motivation tactics and is simple, straightforward. In this paper, we used the contusion method for $\mathrm{SCl}$ model establishment as its easy operation and this is quite similar to $\mathrm{SCl}$ occurs naturally in human. FA and IPT indicate daily intraperitoneal injection of $10 \mathrm{mg} / \mathrm{kg}$ Sal B can significantly repair the motor dysfunction, and, 

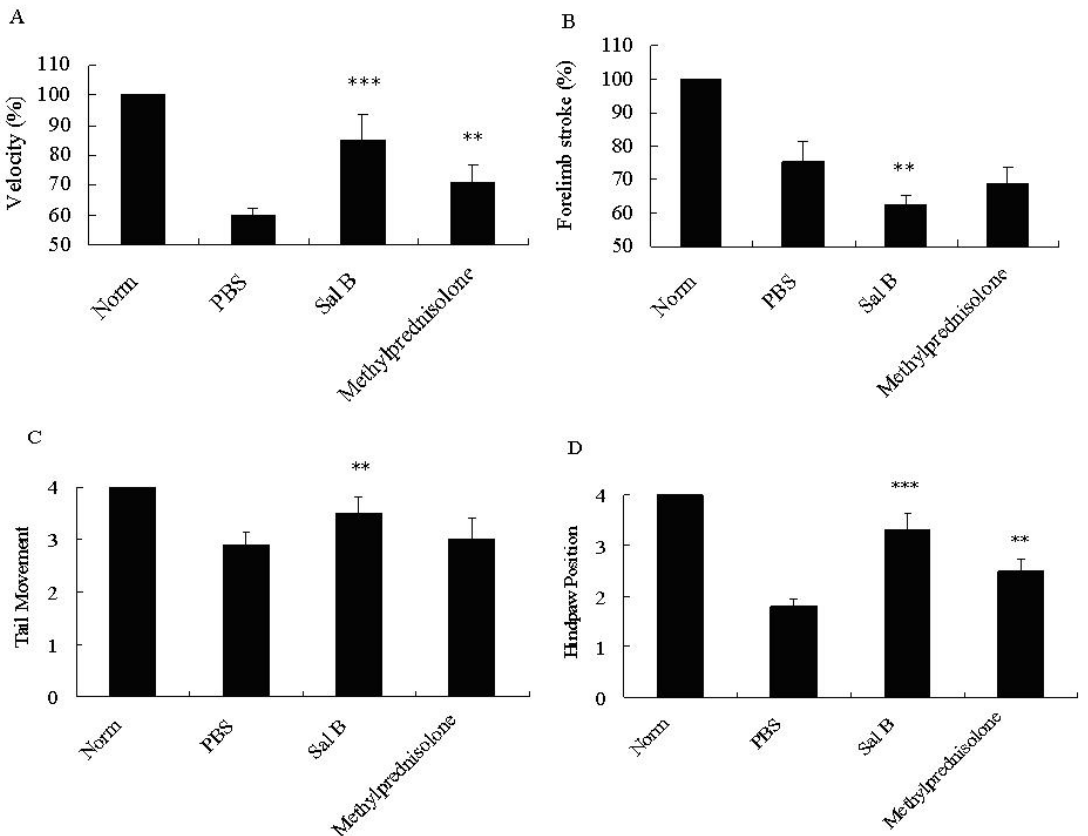

Fig 4: SST of motor function recovery after treatment in contusion SCl rats. (A) Swimming velocity. The mean of three runs obtained from normal rats was taken as $100 \%$ (30 frames). (B) Forelimb strokes. A maximum of 2 forelimb strokes per $60 \mathrm{~cm}$ swimming distance was considered the normal value, representing $100 \%$. One more forelimb stroke decreases the performance by $2 \%$. (C) Tail movement. A score of 4 represents normal tail movements in unlesioned rats, while a completely paretic tail with very rare twitching was given a score of 1 , and a total absence of movement scores 0 . (D) Hindpaw position. The normal swimming position was assigned 4, while the most lateral position was given a score of 1 . Norm: normal rats without SCI. ${ }^{* *} p<0.05 ;{ }^{* * *} p<0.01$

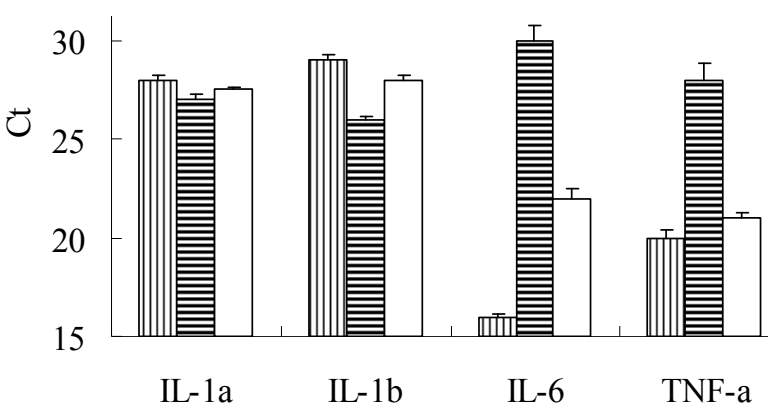

Figure 5: qPCR analysis of cytokines transcription profile of the injured spinal cord after treatment for 1 day. The data represent mean values $(n=3)$ and 2 independent experiments (2 rats for each group). Ct is cycle of threshold, which indicated the abundance of cDNA template transcripted from mRNA. Bars with vertical lines = PBS group; bars with horizontal lines $=$ Sal B group; blank bars = methylprednisolone group

most importantly, 4-week treatment can nearly restore the motor function to normal level.

However, these two tests are too simple to illustrate the thoroughly measurable effectiveness on SCI treatment. Therefore, BBB locomotor rating which is almost exclusively used in this situation was used for evaluation. Indeed, the BBB scale is the most popular method for tracking functional outcome in moderate or mild injury models as well [19]. In general, using this method produces consistent results. That is Sal
B treatment improves motor function, and this beneficial effect is evidently stronger in the former two weeks. When considering more parameters, the effectiveness of Sal B is limited within the cure-period (4 weeks), while BBB rating cannot produce a correct assessment of forelimb-hind limb coordination.

Some researchers successfully used the regularity index $(\mathrm{RI})$ to determinate the functional recovery after $\mathrm{SCl}$ [20], the calculation of $\mathrm{RI}$ is much complicated as it relating to a few factors. Rats can swim naturally, so swimming can be used to obtain objective results in the analysis of motor function after various types of spinal cord lesions. For mild to moderate bilateral dorsal lesions, the assessment of velocity and forelimb strokes can be sufficient to obtain reliable results which correlate with the extent of the lesion or with the degree of recovery after treatment [21]. Swimming also allowed the novel observation in rats of muscle spasms in spinal cord injured rats during the course of recovery [22].

After $\mathrm{SCl}$, one common phenomenon is tissue edema. It seems Sal B eliminates the water content effectively after 3 days. The same result was also obtained in other study [9]. A complex cascade of pathophysiological processes rapidly damage the nervous tissue after initial tramua. Inflammation is one of the major secondary pathologies following $\mathrm{SCl}$ [23], and severe 
inflammatory responses in the injured spinal cord destroy neurons, leading to exacerbate neurodegeneration [24]. Inflammation contributes to secondary damage partly through over-release of cytokines, such as TNF- $\alpha$, which enhance permeability of endothelial cells and facilitate trans-endothelial migration of activated leukocytes to the injured area $[25,26]$. Virtually all nucleated cells, but especially endo/epithelial cells and resident macrophages are potent producers of IL-1, IL-6, and TNF- $\alpha$ [27]. Some cytokines (such as IL-6) can increase up to 1000fold during trauma or infection. The expression of IL-6 is sharply increased in the acute stages after spinal cord injury and it may serve as a factor strongly inducing the differentiation of neural stem cells into astrocytes [28]. In our experiment, the lower IL-6 concentration is related to less SCI as well. Sal B may suppressed the secondary injury by inhibiting the transcription of IL-6 and TNF- $\alpha$, as proposed by other reaserch [9].

Methylprednisolone was the first neuroprotective drug to be discovered, and is the current standard in treatment although its efficacy has been called into question [29]. We used this chemical as a positive control, to compare the effectiveness of Sal B. Other studies reported various drugs for the experimental cure of $\mathrm{SCl}$ $[30,31]$; however, we believe that Sal B is a good competitor considering its multiple usage and the results obtained in this paper.

\section{CONCLUSION}

Sal B is a promising promoter of rat motor dyfunction recovery after estimation by footprint annlysis, inclined plane test, BBB rating and SST analysis. At the same time, Sal B treatment can ameliorate tissue edema and downregulate the transcription of proinflammatory cytokine IL-6 and TNF- $\alpha$.

\section{ACKNOWLEDEGEMENT}

This study was funded by the National Natural Science Foundation of China, no. 81270052.

\section{REFERENCES}

1. Bradbury EJ, McMahon SB. Spinal cord repair strategies: why do they work? Nat. Rev. Neurosci. 2006; 7(8): 644-653.

2. Lowry NA, Temple S. Making human neurons from stem cells after spinal cord injury. PLoS Med. 2007; 4(2): e48

3. Spinal cord injury facts and figures at a glance. J. Spinal Cord Med. 2011 November; 34(6): 620-621. Available from: https://www.nscisc.uab.edu

4. Qiu J. China Spinal Cord Injury Network: changes from within. Lancet Neurol. 2009; 8 (7): 606-607

5. Zhou L. Zuo Z. Chow MS. Danshen: an overview of its chemistry, pharmacology, pharmacokinetics, and clinical use. Journal of Clinical Pharmacology 2005; 45(12): 1345-1359

6. Tian J, Fu F, Li G, Gao Y, Zhang Y, Meng Q, Li C, Liu F. Protections of SMND-309, a novel derivate of salvianolic acid $B$, on brain mitochondria contribute to injury amelioration in cerebral ischemia rats. Phytomedicine 2009; 16(8):726-733.

7. Tian J, Fu F, Li G, Wang Y, Gao Y, Liu Z, Zhang S. SMND309, a novel derivate of salvianolic acid $B$, ameliorates cerebral infarction in rats: characterization and role. Brain Res. 2009; 1263: 114-121.

8. Bi $X B$, Deng $Y B$, Gan $D H$, et al. Salvianolic acid $B$ promotes survival of transplanted mesenchymal stem cells in spinal cord-injured rats. Acta Pharmacol. Sin. 2008; 29(2): 169-176.

9. Ye ZZ, Deng YB, Wu HF, Gan DH. Neuroprotective effects of salvianolic acid $B$ on secondary spinal cord damage. Neural. Regen. Res. 2011; 6(3): 188-192.

10. Guide for the Care and Use of Laboratory Animals:Eighth Edition Available from: http://www.nap.edu/catalog.php?record_id=12910

11. Yamaji T, Yamazaki S, Li J, Price RD, Matsuoka N, Mutoh S. FK1706, a novel nonimmunosuppressant neurophilin ligand, ameliorates motor dysfunction following spinal cord injury through its neuroregenerative action. European Journal of Pharmacology 2008; 591: 147-152.

12. Schiaveto SA, Silva CA, Del Bel EA. Methodological evaluation to analyze functional rec overy after sciatic nerve injury. Neurotrauma 2004; 21(5): 627-135.

13. Voda J, Yamaji T, Gold BG. Neuroimmunophilin ligands improve functional recovery and increase axonal growth afterspinal cord hemisection in rats. J. Neurotrauma 2005; 22(10): 1150-1161.

14. Basso DM, Beattie MS, Bresnahan JC. A sensitive and reliable locomotor rating scale for open field testing in rats. J. Neurotrauma 1995; 12(1): 1-21.

15. Gullo M, Hochreutener E, Schnell D, Scholl J, Schwab ME, Schnell L. The Schnell Swim Test (SST) to measure motor function and recovery in spinal cord injured rats. 2008. Available from: www.noldus.com.

16. Peinnequin A, Mouret C, Birot O, Alonso A, Mathieu J, Clarençon D, Agay D, Chancerelle Y, Multon E. Rat pro-inflammatory cytokine and cytokine related mRNA quantification by real-time polymerase chain reaction using SYBR green. BMC Immunol. 2004; 5: 3

17. Talac $R$, Friedman JA, Moore MJ, Lu L, Jabbari E, Windebank AJ, Currier BL, Yeszemski MJ. Animal models of spinal cord injury for evaluation of tissue engineering strategies. Biomaterials 2004; 25: 15051510.

18. Metz GA, Merkler D, Dietz D, Schwab ME, Fouad K. Efficient testing of motor function in spinal cord injured rats. Brain Res. 2000; 883: 165-177.

19. Thomas CK, Noga BR. Physiological methods to measure motor function in humans and animals with spinal cord injury. J. Rehabil. Res. Dev. 2003; 40(4 Suppl 1): 25-33.

20. Anderson KD, Sharp KG, Hofstadter M, Irvine KA, Murray $M$, Steward

Forelimb locomotor assessment scale (FLAS): novel assessment of forelimb dysfunction after cervical spinal cord injury. Exp. Neurol. 2009; 220(1):23-33.

21. Sedy J, Urdzíkova L, Jendelova P, Sykova E. Methods for behavioral testing of spinal cord injured rats. Neurosci. Biobehav. Rev. 2008; 32: 550-580.

22. Crutcher KA, Gendelman HE, Kipnis J. Is increasing neuroinflammation beneficial for neural repair? J. Neuroimmune Pharmacol. 2006; 1(3): 195-211.

23. Ahn YH, Lee G, Kang SK. Molecular insights of the injured lesions of rat spinal cords: Inflammation, 
apoptosis, and cell survival. Biochem. Biophys. Res. Commun. 2006; 348(2): 560-570.

24. Dasari VR, Veeravalli $K K$, Tsung AJ, et al. Neuronal apoptosis is inhibited by cord blood stem cells after spinal cord injury. J. Neurotrauma 2009; 26(11). 2057-2069.

25. Lopez-Vales $R$, Redensek $A$, Skinner $T A$, et al. Fenretinide promotes functional recovery and tissue protection after spinal cord contusion injury in mice. J. Neurosci. 2010; 30(9): 3220-3226.

26. Dowlati Y, Herrmann $N$, Swardfager $W$, Liu $H$, Sham $L$, Reim EK, Lanctôt KL. A meta-analysis of cytokines in major depression. Bio Psychiatry 2010; 67 (5): 446-457.

27. Nakamura M, Okada S, Toyama Y, Okano H. Role of IL-6 in spinal cord injury in a mouse model. Clin. Rev. Allergy Immunol. 2005; 28(3): 197-204.
28. Blight AR. Miracles and Molecules: Progress in Spinal Cord Repair. Nature Neuroscience Suppl 2002; 5: 1051-1054.

29. Yu CG, Marcillo A, Fairbanks CA, Wilcox GL, Yezierski $R P$. Agmatine improves locomotor function and reduces tissue damage following traumatic spinal cord injury. Neuro. Report 2000; 11: 3203-3207.

30. ArellanoRS, Rios C, Salgado CH, Ménde AM, Del VL, Nava $R C$, Altagracia $M$, Diaz $R$. Metallothioneinll improves motor function recovery a nd increases spared tissue after spinalcord injury in rats. Neurosci. Lett. 2012; 514(1): 102-105.

31. Han JY, Fan JY, Horie Y, Miura S, Cui DH, Ishii H, Hibi T, Tsuneki H, Kimura I. Ameliorating effects of compounds derived from Salvia miltiorrhiza root extract on microcirculatory disturbance and target organ injury by ischemia and reperfusion. Pharmacol. Ther. 2008; 117: 280-295. 